\title{
Moderate dietary sodium restriction added to angiotensin converting enzyme inhibition compared with dual blockade in lowering proteinuria and blood pressure: randomised controlled trial
}

\author{
Maartje C J Slagman internist in training ${ }^{1}$, Femke Waanders internist in training ${ }^{1}$, Marc $\mathrm{H}$ Hemmelder \\ internist in training ${ }^{2}$, Arend-Jan Woittiez internist-nephrologist ${ }^{3}$, Wilbert M T Janssen \\ internist-nephrologist ${ }^{4}$, Hiddo J Lambers Heerspink pharmacist ${ }^{5}$, Gerjan Navis internist-nephrologist ${ }^{1}$, \\ Gozewijn D Laverman internist-nephrologist, HONEST coordinator ${ }^{13}$, for the HONEST (HOlland \\ NEphrology STudy) Group
}

${ }^{1}$ Department of Internal Medicine, Division of Nephrology, University Medical Center Groningen, Netherlands; ${ }^{2}$ Department of Internal Medicine, Division of Nephrology, Medical Center Leeuwarden, Netherlands; ${ }^{3}$ Department of Internal Medicine, Division of Nephrology, ZGT Hospital Almelo, Netherlands; ${ }^{4}$ Department of Internal Medicine, Division of Nephrology, Martini Hospital Groningen; ${ }^{5}$ Department of Pharmacology, University Medical Center Groningen

\begin{abstract}
Objective To compare the effects on proteinuria and blood pressure of addition of dietary sodium restriction or angiotensin receptor blockade at maximum dose, or their combination, in patients with non-diabetic nephropathy receiving background treatment with angiotensin converting enzyme (ACE) inhibition at maximum dose.

Design Multicentre crossover randomised controlled trial.

Setting Outpatient clinics in the Netherlands.

Participants 52 patients with non-diabetic nephropathy.

Interventions All patients were treated during four 6 week periods, in random order, with angiotensin receptor blockade (valsartan $320 \mathrm{mg} / \mathrm{day}$ ) or placebo, each combined with, consecutively, a low sodium diet (target $50 \mathrm{mmol} \mathrm{Na}^{+} /$day) and a regular sodium diet (target $200 \mathrm{mmol} \mathrm{Na}+$ day), with a background of ACE inhibition (lisinopril $40 \mathrm{mg} /$ day) during the entire study. The drug interventions were double blind; the dietary interventions were open label.

Main outcome measures The primary outcome measure was proteinuria; the secondary outcome measure was blood pressure.

Results Mean urinary sodium excretion, a measure of dietary sodium intake, was 106 (SE 5) mmol Na+dday during a low sodium diet and 184 (6) $\mathrm{mmol} \mathrm{Na} /$ day during a regular sodium diet $(\mathrm{P}<0.001)$. Geometric mean residual proteinuria was 1.68 (95\% confidence interval 1.31 to 2.14) $\mathrm{g}$ /day during $A C E$ inhibition plus a regular sodium diet. Addition of angiotensin receptor blockade to ACE inhibition reduced proteinuria to 1.44 (1.07 to 1.93$) \mathrm{g} /$ day $(\mathrm{P}=0.003)$, addition of a low sodium diet reduced it to 0.85 ( 0.66 to 1.10$) \mathrm{g} /$ day $(\mathrm{P}<0.001)$, and addition of angiotensin receptor blockade plus a low sodium diet reduced it to 0.67
\end{abstract}

( 0.50 to 0.91$) \mathrm{g} /$ day $(\mathrm{P}<0.001)$. The reduction of proteinuria by the addition of a low sodium diet to ACE inhibition (51\%, 95\% confidence interval $43 \%$ to $58 \%)$ was significantly larger $(P<0.001)$ than the reduction of proteinuria by the addition of angiotensin receptor blockade to ACE inhibition $(21 \%$, ( $8 \%$ to $32 \%)$ and was comparable $(\mathrm{P}=0.009$, not significant after Bonferroni correction) to the reduction of proteinuria by the addition of both angiotensin receptor blockade and a low sodium diet to ACE inhibition (62\%, 53\% to $70 \%$ ). Mean systolic blood pressure was 134 (3) $\mathrm{mm} \mathrm{Hg}$ during ACE inhibition plus a regular sodium diet. Mean systolic blood pressure was not significantly altered by the addition of angiotensin receptor blockade (131 (3) $\mathrm{mm} \mathrm{Hg} ; \mathrm{P}=0.12$ ) but was reduced by the addition of a low sodium diet (123 (2) $\mathrm{mm} \mathrm{Hg} ; \mathrm{P}<0.001$ ) and angiotensin receptor blockade plus a low sodium diet (121 (3) mm $\mathrm{Hg} ; \mathrm{P}<0.001)$ to ACE inhibition. The reduction of systolic blood pressure by the addition of a low sodium diet (7\% (SE 1\%)) was significantly larger $(P=0.003)$ than the reduction of systolic blood pressure by the addition of angiotensin receptor blockade $(2 \%(1))$ and was similar $(P=0.14)$ to the reduction of systolic blood pressure by the addition of both angiotensin receptor blockade and low sodium diet (9\% (1)), to ACE inhibition.

Conclusions Dietary sodium restriction to a level recommended in guidelines was more effective than dual blockade for reduction of proteinuria and blood pressure in non-diabetic nephropathy. The findings support the combined endeavours of patients and health professionals to reduce sodium intake.

Trial registration Netherlands Trial Register NTR675. 


\section{Introduction}

In patients with chronic kidney disease, blockade of the renin-angiotensin-aldosterone system with an angiotensin converting enzyme (ACE) inhibitor or angiotensin receptor blocker provides long term renal and cardiovascular protection, apparently through the effects on blood pressure and proteinuria. ${ }^{1-3}$ On the basis of the finding that outcome is related to the achieved blood pressure and proteinuria, ${ }^{4-6}$ guidelines recommend a blood pressure below $125 / 75 \mathrm{~mm} \mathrm{Hg}$ in patients with residual proteinuria exceeding $1.0 \mathrm{~g} / \mathrm{day}$, with reduction of proteinuria to below $1.0 \mathrm{~g} /$ day as an independent target. ${ }^{4}$

Blockade of the renin-angiotensin-aldosterone system with monotherapy seems to be insufficiently effective for a large proportion of patients. ${ }^{89}$ Several potential strategies aim to lower blood pressure and proteinuria on top of ACE inhibition or angiotensin receptor blockade. ${ }^{71} 11$ These include increasing the dose to higher than the top of the dose-response curve for blood pressure for a better antiproteinuric response, ${ }^{12-14}$ addition of a second renin-angiotensin-aldosterone system blocker (dual blockade), ${ }^{8} 1415$ and correction of excess extracellular volume by dietary sodium restriction, diuretics, or both. ${ }^{16-24}$ Several studies in chronic kidney disease have shown an added effect of dual blockade on blood pressure and proteinuria, ${ }^{814}{ }^{15}$ but this effect is very modest if dose titration of the single drugs was sufficient, ${ }^{25}$ and the long term effect is still unclear. ${ }^{26} 27$ Addition of dietary sodium restriction might be more effective than dual blockade and is rational because dietary sodium intake in patients with renal disease is usually considerably above the recommended values. ${ }^{28-30}$ However, the effects of dietary sodium restriction and dual blockade have not been tested head to head. Therefore, we tested head to head which of the two additional interventions - dietary sodium restriction and angiotensin receptor blockade - is more effective in reaching the treatment targets for proteinuria and blood pressure in patients with renal disease already treated with ACE inhibition at the maximum recommended dose. We also evaluated the efficacy of combining dietary sodium restriction and dual blockade.

\section{Methods}

\section{Study design}

The HOlland NEphrology Study (HONEST) Group did a randomised, double blind, placebo controlled, crossover trial between April 2006 and October 2009 in three medical centres. The primary outcome measure of the trial was proteinuria, and the secondary outcome measure was blood pressure. All participants gave written informed consent. The study sponsor provided trial drugs at no cost.

\section{Participants}

We screened consecutive patients with renal disease who visited the nephrology outpatient clinics for the presence of non-diabetic nephropathy, as confirmed by analysis of blood and urine or renal biopsy. Inclusion criteria were blood pressure above $125 / 75 \mathrm{~mm} \mathrm{Hg}$ in combination with residual proteinuria above $1.0 \mathrm{~g} /$ day during ACE inhibition at maximal dose (lisinopril 40 $\mathrm{mg} /$ day), creatinine clearance of $30 \mathrm{~mL} / \mathrm{min}$ or above, and age over 18 years. For safety reasons, we excluded patients with systolic blood pressure of $180 \mathrm{~mm} \mathrm{Hg}$ or above, diastolic blood pressure of $110 \mathrm{~mm} \mathrm{Hg}$ or above, or both. Other exclusion criteria were diabetes mellitus, renovascular hypertension, decrease of creatinine clearance by at least $6 \mathrm{~mL} / \mathrm{min}$ in the previous year, a cardiovascular event in the previous six months, immunosuppressive treatment, regular use ( $>1$ day/week) of non-steroidal anti-inflammatory drugs, pregnancy, or breast feeding.

\section{Treatment}

During a run-in period of at least six weeks, patients received ACE inhibition at maximal dose (lisinopril $40 \mathrm{mg} /$ day) and stopped all other renin-angiotensin-aldosterone system blockers. Additional antihypertensive drugs such as $\beta$ blockers, $\alpha$ blockers, calcium channel blockers, and diuretics were allowed and kept stable during the study (table 1). No dietary intervention took place during the run-in period.

After the run-in period, patients were treated during four treatment periods of six weeks with, consecutively, ACE inhibition at maximal dose (lisinopril $40 \mathrm{mg}$ /day) plus placebo and ACE inhibition plus angiotensin receptor blockade at maximal dose (lisinopril $40 \mathrm{mg}$ /day plus valsartan $320 \mathrm{mg} /$ day). Both treatments were combined with, consecutively, a low sodium diet (target sodium intake $50 \mathrm{mmol} \mathrm{Na} /$ day; approximately $1200 \mathrm{mg} \mathrm{Na}^{+} /$day or $3 \mathrm{~g} \mathrm{NaCl} /$ day) and a regular sodium diet (target sodium intake $200 \mathrm{mmol} \mathrm{Na}^{+} /$day; $4800 \mathrm{mg}$ $\mathrm{Na}^{+} /$day or $12 \mathrm{~g} \mathrm{NaCl} /$ day). The drug interventions were double blind, whereas the dietary interventions were open label.

To prevent systematic errors resulting from the crossover design, the different treatment periods were done in random order. Because of this randomisation and the rather short half life of the interventions (lisinopril 12.6 hours, valsartan 9 hours, low sodium diet $<1$ week $^{31}$ ), the protocol did not include wash-out periods.

We defined four different treatment sequences as follows. (1) Placebo plus low sodium diet, valsartan plus low sodium diet, valsartan plus regular sodium diet, placebo plus regular sodium diet. (2) Placebo plus regular sodium diet, valsartan plus regular sodium diet, valsartan plus low sodium diet, placebo plus low sodium diet. (3) Valsartan plus regular sodium diet, placebo plus regular sodium diet, placebo plus low sodium diet, valsartan plus low sodium diet. (4) Valsartan plus low sodium diet, placebo plus low sodium diet, placebo plus regular sodium diet, valsartan plus regular sodium diet. An independent pharmacist randomised these sequences, using a computer program. We implemented the random allocation sequence by means of sequentially numbered containers of study drug. Physicians enrolled patients, and the pharmacist allocated the study drug sequentially to consecutive participants. The randomisation code remained secret during the entire study; all participants, investigators, and care providers were blinded, except for the pharmacist.

Physicians gave the participants a list of food products that are commonly consumed in the Netherlands, together with their sodium content, at the time of inclusion. Diverse professional dietitians gave further dietary counselling in various autonomous dietary practices in the community. Except for a request to achieve the particular sodium targets (that is, $50 \mathrm{mmol} \mathrm{Na}+$ day during the low sodium diet and $200 \mathrm{mmol} \mathrm{Na}^{+} /$day during the regular sodium diet), dietitians did not receive extra training or a script for this study. Each patient had two to four dietary counselling sessions. Individualised counselling used the general principle of remaining as close as possible to the patients' preferences and nutritional habits, to increase feasibility and compliance, taking into account adequacy of nutritional requirements as well as sodium content. For the periods on the regular sodium diet, the patients were advised to maintain their habits regarding sodium intake. For the periods on the low sodium diet, patients were advised not to add any salt to their food and to replace sodium rich products with sodium poor 
products. We monitored compliance by 24 hour urinary sodium excretion and informed the physician, patients, and dietitians of these results.

\section{Measurements and calculations}

At the end of each six week treatment period, patients collected 24 hour urine samples and blood pressure was measured and blood sampled after an overnight fast. Additionally, in the middle of every six week treatment period, patients collected 24 hour urine samples to monitor dietary compliance.

We measured proteinuria in 24 hour urine samples with a turbidimetric assay using benzethonium chloride (Modular, Roche Diagnostics, Mannheim, Germany). We measured blood pressure at one minute intervals with an automatic device (Dinamap, G E Medical Systems, Milwaukee, WI, USA) with the patient in a supine position. After 15 minutes of measurements, we used the mean of the last three readings for further analysis. We determined blood electrolytes, lipids, proteins, and urinary electrolytes by using an automated multianalyser (Modular, Roche Diagnostics, Mannheim, Germany). We assessed dietary sodium intake from urinary sodium excretion. We calculated creatinine clearance from creatinine concentrations in plasma and in 24 hour urine samples. We used the Maroni formula to assess dietary protein intake from urinary urea excretion. ${ }^{32}{ }^{33} \mathrm{We}$ assessed peripheral pitting oedema at the pretibial area of both legs by visual and manual examination and scored it as absent or present.

\section{Statistical analysis}

We expected that patients would present with a mean proteinuria of approximately $2 \mathrm{~g}$ /day during ACE inhibition. On the basis of previous studies, we assumed a $35 \%$ reduction in proteinuria by addition of a low sodium diet on top of ACE inhibition plus angiotensin receptor blockade and a standard deviation of 0.75 in log transformed proteinuria response..$^{8251617}{ }^{20}$ From these numbers, we estimated that 51 patients had to complete the crossover design to provide $90 \%$ power to detect a statistically significant difference. We used a significance level of $\alpha=0.0083$ (rather than $\alpha=0.05$ ) to adjust for six primary comparisons of interest. To account for a $10 \%$ dropout rate during the trial, we would need to include 56 patients (PASS 10, NCCS, East Kaysville, UT, USA). Of note, the sample size is smaller than would have been needed in a non-crossover study, as the same patient provides data for each treatment group and this increases power, owing to the smaller within patient variability than between group variability. ${ }^{34} 35$

We analysed data for the 52 patients who completed the trial, and we present these data here. Additionally, we analysed the data for all 54 patients who were included (intention to treat). As the effect estimates and confidence intervals were very similar and the statistical and clinical conclusions did not change, we have not shown these data. Before statistical testing, we natural $\log$ transformed skewed variables to obtain normality. We determined differences between the four different treatment sequences by using one way analysis of variance with Bonferroni's post hoc tests and Pearson's $\chi^{2}$ tests. We used paired $t$ tests (which account for the same patients providing data for both treatment groups) to determine the effects of treatment. We did six comparisons for each parameter: ACE inhibition versus ACE inhibition plus angiotensin receptor blockade, ACE inhibition versus ACE inhibition plus low sodium diet, ACE inhibition versus ACE inhibition plus angiotensin receptor blockade plus low sodium diet, ACE inhibition plus angiotensin receptor blockade versus ACE inhibition plus low sodium diet, ACE inhibition plus angiotensin receptor blockade versus ACE inhibition plus angiotensin receptor blockade plus low sodium diet, and ACE inhibition plus low sodium diet versus ACE inhibition plus angiotensin receptor blockade plus low sodium diet. To allow for multiple testing, we set the type I error $(\alpha)$ at 0.0083 (Bonferroni correction) for analyses of the primary outcome (proteinuria). Furthermore, we did a linear mixed model analysis to check for carryover effects, with $\log$ transformed proteinuria as a dependent variable, participants as a random factor, and treatment and sequence as well as their interaction (treatment*sequence) as fixed factors.

We give data as mean with standard error (SE) when normally distributed or as geometric mean with $95 \%$ confidence interval when skewed. We report only unadjusted $P$ values. We used SPSS 16.0 for Windows for all analyses.

\section{Results}

\section{Study population}

We assessed 71 patients for eligibility. Of these, 13 patients declined to participate and 58 patients gave informed consent and started the run-in period. During the run-in period, two patients discontinued because of symptomatic hypotension and two patients were withdrawn because of complete reduction of proteinuria. Of the 54 patients who were randomised, one patient was withdrawn because of a rash after starting valsartan and one patient discontinued because of lack of motivation to adhere to the low sodium diet. Finally, 52 patients completed the study and were included in the analyses. Table 1 shows baseline characteristics. Non-study drugs were kept stable during the study.

Before entry into the study, 14 of the 52 patients used a $\beta$ blocker, whereas 12 patients were using a $\beta$ blocker at the end of the run-in period (and during the rest of the study). The equivalent numbers were 10 versus 10 patients for calcium channel blockers, 5 versus 6 for $\alpha$ blockers, 24 versus 8 for thiazide diuretics, 9 versus 5 for loop diuretics, 36 versus 52 for ACE inhibitors, and 29 versus 0 for angiotensin receptor blockers.

\section{Compliance and efficacy}

We assessed compliance from 24 hour urine samples and from pill counts. Urinary creatinine excretion was comparable during all treatment periods, indicating accurate 24 hour urine sample collection (table 2). Mean dietary sodium intake, as assessed from urinary sodium excretion, was 106 (SE 5) $\mathrm{mmol} \mathrm{Na}^{+} /$day (approximately $2500 \mathrm{mg} \mathrm{Na}^{+} /$day or $6 \mathrm{~g} \mathrm{NaCl} /$ day) during the periods on a low sodium diet and 184 (6) $\mathrm{mmol} \mathrm{Na}^{+} /$day $(4400$ $\mathrm{mg} \mathrm{Na}^{+} /$day or $11 \mathrm{~g} \mathrm{NaCl} /$ day; $\mathrm{P}<0.001 v$ low sodium diet) during the periods on the regular sodium diet. All patients adhered to the pharmaceutical intervention ( $>85 \%$ of valsartan and placebo capsules taken during each study period), except for two patients who took only $60-70 \%$ of the blinded study drug during the four different treatment periods. We included all 52 patients in the analyses.

The addition of a low sodium diet to ACE inhibition decreased body weight (from mean 89 (SE 3) kg to 87 (2) kg; $\mathrm{P}<0.001$ ) and plasma sodium (from 140.7 (SE 0.4) mmol/L to 139.5 (0.4) $\mathrm{mmol} / \mathrm{L} ; \mathrm{P}=0.001)$ and tended to reduce the prevalence of peripheral oedema (from $18(35 \%)$ patients to $8(15 \%)$; $\mathrm{P}=0.057$ ), and increased plasma albumin (from 38 (1) $\mathrm{g} / \mathrm{L}$ to 40 (1) $\mathrm{g} / \mathrm{L} ; \mathrm{P}<0.001$ ) and total protein (from 68 (1) $\mathrm{g} / \mathrm{L}$ to 71 (1) $\mathrm{g} / \mathrm{L} ; \mathrm{P}<0.001)$, consistent with a negative sodium balance. 
Addition of angiotensin receptor blockade to ACE inhibition did not affect these parameters, whereas addition of angiotensin receptor blockade plus a low sodium diet to ACE inhibition had approximately the same effect as addition of a low sodium diet alone (table 2). Dietary protein intake, as assessed from urinary urea excretion, was $1.02(0.04) \mathrm{g} / \mathrm{kg} / \mathrm{day}$ during ACE inhibition. It was not altered by the addition of angiotensin receptor blockade (1.01 (0.04) g/kg/day; $\mathrm{P}=0.99)$ but was slightly reduced by the addition of a low sodium diet $(0.96(0.04) \mathrm{g} / \mathrm{kg} / \mathrm{day}$; $\mathrm{P}=0.004$ ) or a low sodium diet plus angiotensin receptor blockade $(0.91(0.03) \mathrm{g} / \mathrm{kg} /$ day; $\mathrm{P}<0.001)$ to ACE inhibition.

\section{Proteinuria (primary outcome)}

During ACE inhibition combined with the regular sodium diet, geometric mean residual proteinuria was 1.68 (95\% confidence interval 1.31 to 2.14 ) g/day (fig 1). Addition of angiotensin receptor blockade reduced proteinuria to 1.44 (1.07 to 1.93 ) $\mathrm{g} /$ day $(\mathrm{P}=0.003)$, and addition of a low sodium diet reduced it to $0.85(0.66$ to 1.10$) \mathrm{g} / \mathrm{day}(\mathrm{P}<0.001)$. The lowest level of residual proteinuria $(0.67(0.50$ to 0.91$) \mathrm{g} /$ day; $\mathrm{P}<0.001)$ was achieved by the addition of angiotensin receptor blockade plus a low sodium diet. Moreover, the reduction of proteinuria by the addition of a low sodium diet to ACE inhibition (reduction of $51 \%$ ( $95 \%$ confidence interval $43 \%$ to $58 \%$ ) was significantly larger $(\mathrm{P}<0.001)$ than the reduction of proteinuria by the addition of angiotensin receptor blockade to ACE inhibition (reduction of $21 \%$ ( $8 \%$ to $32 \%$ ). However, the reduction of proteinuria by the addition of both a low sodium diet and angiotensin receptor blockade to ACE inhibition (reduction of $62 \%$ (53\% to $70 \%$ ) was not significantly larger $(\mathrm{P}=0.009$, not significant after Bonferroni correction) than the reduction of proteinuria by the addition of only a low sodium diet to ACE inhibition. In an additional linear mixed model analysis, we verified the absence of carryover effects. Treatment was a significant determinant of residual proteinuria $(\mathrm{P}<0.001)$, whereas sequence $(\mathrm{P}=0.52)$ and treatment*sequence $(\mathrm{P}=0.98)$ were not. We found similar results for urinary protein/creatinine ratio (table 2 ).

\section{Secondary outcomes}

Systolic and diastolic blood pressure were above the target of $125 / 75 \mathrm{~mm} \mathrm{Hg}$ during ACE inhibition combined with the regular sodium diet. Mean systolic blood pressure was 134 (SE 3) mm $\mathrm{Hg}$ during ACE inhibition (fig 2). Addition of angiotensin receptor blockade did not significantly alter systolic blood pressure (131 (3) $\mathrm{mm} \mathrm{Hg} ; \mathrm{P}=0.12$ ), whereas addition of a low sodium diet reduced systolic blood pressure to 123 (2) $\mathrm{mm} \mathrm{Hg}$ $(\mathrm{P}<0.001)$ and addition of both angiotensin receptor blockade and a low sodium diet reduced systolic blood pressure to 121 (3) $\mathrm{mm} \mathrm{Hg}(\mathrm{P}<0.001)$. Moreover, the reduction of systolic blood pressure by the addition of a low sodium diet to ACE inhibition (reduction of 7\% (SE 1\%)) was significantly larger $(\mathrm{P}=0.003)$ than that achieved by the addition of angiotensin receptor blockade to ACE inhibition (reduction of $2 \%(1 \%)$ ). However, the reduction of systolic blood pressure by the addition of both a low sodium diet and angiotensin receptor blockade to ACE inhibition (reduction of 9\% (1\%)) was not significantly larger $(\mathrm{P}=0.14)$ than that achieved by the addition of only a low sodium diet to ACE inhibition (reduction of 7\% (1\%)).

Mean diastolic blood pressure was 80 (SE 2) mm Hg during ACE inhibition combined with the regular sodium diet (fig 3 ). Diastolic blood pressure was slightly reduced by the addition of angiotensin receptor blockade (77 (2) $\mathrm{mm} \mathrm{Hg}$; decrease of $4 \%(2 \%) ; \mathrm{P}=0.02)$ and was considerably reduced by addition of a low sodium diet (73 (2) $\mathrm{mm} \mathrm{Hg}$; decrease of $8 \%$ (2\%); $\mathrm{P}<0.001)$ and by the addition of angiotensin receptor blockade plus a low sodium diet (71 (2) mm Hg; decrease of 11\% (2\%); $\mathrm{P}<0.001)$.

Renal function was relatively preserved during ACE inhibition combined with the regular sodium diet (geometric mean creatinine clearance 72 (62 to 84 ) $\mathrm{mL} / \mathrm{min}$; mean plasma creatinine 137 (8) $\mu \mathrm{mol} / \mathrm{L}$ ). Renal function was not significantly altered by the addition of angiotensin receptor blockade (creatinine clearance 74 (65 to 84 ) $\mathrm{mL} / \mathrm{min} ; \mathrm{P}=0.65$ ), but decreased when a low sodium diet (66 (57 to 76$) \mathrm{mL} / \mathrm{min}$; $\mathrm{P}=0.002)$ or angiotensin receptor blockade plus a low sodium diet (61 (53 to 70$) \mathrm{mL} / \mathrm{min} ; \mathrm{P}<0.001)$ was added to ACE inhibition; this effect was reversible on withdrawal of the low sodium diet and angiotensin receptor blockade (not shown).

Mean plasma potassium was $4.6(0.1) \mathrm{mmol} / \mathrm{L}$ during ACE inhibition combined with the regular sodium diet and was not significantly changed by the addition of angiotensin receptor blockade $(4.6(0.1) \mathrm{mmol} / \mathrm{L} ; \mathrm{P}=0.09)$, whereas addition of a low sodium diet $(4.7(0.1) \mathrm{mmol} / \mathrm{L} ; \mathrm{P}=0.03)$ or angiotensin receptor blockade plus a low sodium diet $(5.0$ (0.1) mmol/L; $\mathrm{P}<0.001)$ increased plasma potassium concentrations. Potassium concentrations in the lower range $(<4.0 \mathrm{mmol} / \mathrm{L})$ were present in eight patients during ACE inhibition combined with the regular sodium diet and in two patients during ACE inhibition plus angiotensin receptor blockade plus a low sodium diet. Potassium concentrations in the higher range $(>5.5 \mathrm{mmol} / \mathrm{L})$ were present in three patients during ACE inhibition combined with the regular sodium diet and in 10 patients during ACE inhibition plus angiotensin receptor blockade plus a low sodium diet.

Severe orthostatic complaints occurred in two patients during the first treatment period, which was ACE inhibition plus angiotensin receptor blockade plus low sodium diet for one patient and ACE inhibition plus low sodium diet for the other. The complaints were resolved by tapering of lisinopril to 20 $\mathrm{mg} /$ day. In these patients, the dose of lisinopril was kept stable at $20 \mathrm{mg}$ /day during the rest of the treatment periods. In five other patients, mild orthostatic complaints not necessitating drug withdrawal occurred: in three patients during ACE inhibition plus angiotensin receptor blockade plus low sodium diet and in two patients during ACE inhibition plus low sodium diet. Dry cough occurred in one patient and was present during all study periods. These complaints resolved on tapering of ACE inhibition after the last study period.

\section{Discussion}

This study provides the first head to head comparison of moderate dietary sodium restriction, add-on angiotensin receptor blockade, and their combination, as measures to improve the therapeutic effect of angiotensin converting enzyme (ACE) inhibition. In patients with non-diabetic renal disease with insufficient control of proteinuria and blood pressure despite maximally dosed ACE inhibition monotherapy, addition of maximally dosed angiotensin receptor blockade had a modest added effect on proteinuria, without effects on systolic blood pressure. Addition of a low sodium diet to ACE inhibition induced a considerable reduction of proteinuria and blood pressure, and a slight additional reduction of proteinuria occurred during a low sodium diet combined with dual blockade. These data show, firstly, that moderate dietary sodium restriction added to ACE inhibition is more effective to reach proteinuria and blood pressure targets than is dual blockade and, secondly, that a low sodium diet also improves proteinuria and blood pressure during dual blockade. 


\section{Comparison with other studies}

Our findings on dual blockade and a low sodium diet are in line with previous studies in chronic kidney disease. A meta-analysis found no differences in systolic and diastolic blood pressure between ACE inhibition plus angiotensin receptor blockade and ACE inhibition alone. ${ }^{15}$ In another meta-analysis, proteinuria was on average $22 \%$ (16\% to $28 \%$ ) lower during ACE inhibition plus angiotensin receptor blockade than during ACE inhibition. ${ }^{8}$ In previous studies of dietary sodium intervention, blood pressure was on average 3\% to 9\% lower during ACE inhibition (or angiotensin receptor blockade) combined with a low sodium diet than during ACE inhibition (or angiotensin receptor blockade) combined with a regular sodium diet, and proteinuria was $31 \%$ to $40 \%$ lower. $^{16} 172021$ In these studies, the urinary sodium excretion, reflecting dietary sodium intake, was in the same range as in our study, supporting the generalisability of our findings in renal populations.

\section{Other outcome measures}

Plasma potassium concentrations were unaffected by addition of angiotensin receptor blockade to ACE inhibition but increased by addition of a low sodium diet or angiotensin receptor blockade plus a low sodium diet. This may be relevant given the previously shown $U$ shaped relation between plasma potassium and outcome in patients with renal disease, with a higher risk of end stage renal disease and death at potassium concentrations below $4.0 \mathrm{mmol} / \mathrm{L}$ and a higher risk of cardiovascular events and death at concentrations exceeding $5.5 \mathrm{mmol} / \mathrm{L} .{ }^{36}{ }^{37}$ Increases in potassium might be beneficial in patients with initial plasma potassium in the lower range $(15 \%$ of our patients) and a potential threat in patients with initial plasma potassium in the higher range ( $6 \%$ of our patients) and would require careful monitoring.

Renal function was not significantly altered by addition of angiotensin receptor blockade to ACE inhibition but decreased by addition of a low sodium diet or angiotensin receptor blockade plus a low sodium diet. This decline in renal function was reversible and probably reflects a fall in glomerular pressure. No evidence suggests that such an effect is harmful; in contrast, it has been associated with a slower subsequent decline in renal function. ${ }^{38-41}$ This relation between a treatment induced short term decline in renal function and long term preservation of renal function seems to hold for increases in plasma creatinine of up to $30 \%$ in people with creatinine exceeding $124 \mu \mathrm{mol} / \mathrm{L}(1.4 \mathrm{mg} / \mathrm{dL}),{ }^{40}$ which was the case in our patients.

Orthostatic complaints occurred in seven of our 52 patients, during the regimens with the strongest antihypertensive effect (that is, during dual or single blockade combined with the low sodium diet but not during the regular sodium diet). Only two patients needed tapering of ACE inhibition.

\section{Diuretic treatment}

The effect of a low sodium diet added to ACE inhibition is probably due to a correction of excess extracellular volume. An alternative approach is diuretic treatment or combination treatment. ${ }^{16171921}$ Interestingly, up-titration of diuretic combined with half doses of ACE inhibition plus angiotensin receptor blockade was recently found to reduce proteinuria better than ACE inhibition plus up-titration of angiotensin receptor blockade to full dose. ${ }^{42}$ Moreover, we previously showed that the combination of a low sodium diet and diuretics was more effective than either alone. ${ }^{16}$ In this study, we applied only the low sodium diet, but patients who needed diuretics during the run-in period to control oedema continued this treatment at a fixed dose. For the treatment protocol, we refrained from combining a low sodium diet and diuretics to avoid excessive volume depletion, and associated adverse effects on blood pressure and renal function, during the maximal pharmacological blockade of the renin-angiotensin-aldosterone system. Thus, in individual patients with insufficient response to dual blockade plus a low sodium diet, the response could probably be improved by adding a diuretic, with monitoring of tolerability.

\section{Strengths and limitations of study}

This study provides the first head to head comparison of moderate dietary sodium restriction, add-on angiotensin receptor blockade, and their combination, as measures to improve the therapeutic effect of ACE inhibition. We selected patients with high residual risk during ACE inhibition monotherapy, which is precisely the target population for added measures and thus clinically relevant. ${ }^{89}$ Reduction of blood pressure and proteinuria in the range seen here has previously been shown to predict a better renal and cardiovascular outcome. ${ }^{236}$

We aimed to optimise the applicability of our results to clinical practice by doing the dietary intervention in an outpatient setting that reflects the usual nephrology care, with relatively simple dietary measures, replacing sodium rich food components with sodium poor products. In line with previous studies, regular sodium intake was well above the recommended intake. ${ }^{28-30}$ Our dietary intervention policy did not result in the target of $50 \mathrm{mmol}$ $\mathrm{Na}^{+} /$day, but a substantial reduction in sodium intake to values in line with the guidelines for renal patients was nevertheless achieved. ${ }^{43}$ This supports the applicability of our results to clinical practice.

Furthermore, we used maximal doses of ACE inhibition and angiotensin receptor blockade to ensure a maximal effect of the dual blockade on both blood pressure and proteinuria, because sub-maximal dosing hampers interpretation of many studies on dual blockade. Thus, the stronger effect of the low sodium diet cannot be attributed to a suboptimal dual blockade regimen.

The main limitation of the study is that it provides only short term data and no hard end points. Also, the population was relatively small, although this is the largest study of sodium intervention in proteinuric patients so far. Furthermore, we excluded patients with diabetes because of possible heterogeneity in the renal response to sodium restriction. ${ }^{44}$ These characteristics limit the generalisability of our data. Of note, a separate study in patients with diabetic proteinuria is ongoing (trial number NTR2366, www.trialregister.nl/trialreg/admin/ rctsearch.asp?Term=dinamo).

The sodium intervention was done in a way that closely mimics clinical care in the outpatient setting. For the periods on the regular sodium diet, the patients were advised to maintain their habits regarding sodium intake. For the periods on the low sodium diet, patients were advised not to add any salt to their food and to replace sodium rich products with sodium poor products. Accordingly, the lower proteinuria and blood pressure cannot specifically be attributed to the lower sodium intake, as inadvertent changes in other food components might be involved. However, such changes are likely to occur in clinical practice as well.

From the relevant food components that could be documented in 24 hour urine samples, potassium intake did not change. Urinary urea excretion was reduced during the low sodium diet, suggesting a somewhat lower protein intake. Hence, a lower protein intake may have contributed to the beneficial effect on proteinuria, ${ }^{45}$ although the direct effect of the low sodium diet 
on blood pressure, during both monotherapy and dual blockade, seems likely to be the main driving force for reduction in proteinuria. Urinary calcium excretion was lower during low sodium periods. We cannot exclude a lower calcium intake, but the lower calciuria is in line with corresponding findings in other populations, where it is attributed to altered renal calcium handling. ${ }^{47}$ At any rate, the lower blood pressure during low sodium periods is not likely to be due to an inadvertent higher calcium intake.

Finally, as the study was not powered on blood pressure, we cannot exclude the possibility that the absence of a significant effect of add-on angiotensin receptor blockade on blood pressure may be due to a lack of power.

\section{Policy implications}

Our data clearly show that a moderate restriction of dietary sodium intake, which is feasible in routine nephrology care, is more effective than dual renin-angiotensin-aldosterone system blockade for control of blood pressure and proteinuria in chronic kidney disease, with an acceptable rate of adverse effects. Whether this translates into improved outcome in chronic kidney disease should be investigated in a well powered study with sufficiently long term follow-up. This is all the more relevant because long term results of dual blockade have turned out to be unreliable or controversial, ${ }^{26}{ }^{27} 48$ whereas the long term benefits of dietary sodium restriction are increasingly appreciated. ${ }^{11}{ }^{49-52}$ Of note, the range of sodium intake associated with a more favourable long term health outcome in the literature is not excessively low, with respect to both spontaneous intake and after intervention, ${ }^{28}{ }^{49}$ and corresponds to level of sodium restriction obtained in our study. This implies that general efforts to implement guidelines for sodium intake, as recently emphasised for the general population, ${ }^{51}$ will have the potential to greatly improve health outcomes in patients with chronic renal disease. As renin-angiotensin-aldosterone system blockade is also a mainstay of treatment in essential hypertension, diabetic nephropathy, and heart failure, investigating the potential of sodium restriction to enhance the efficacy of such blockade in these populations as well would be of great interest.

\section{Conclusions}

Moderate dietary sodium restriction was more effective than the addition of maximal dose angiotensin receptor blockade for control of proteinuria and blood pressure in patients with renal disease on a maximal dose of ACE inhibition. Dual blockade should not be instituted in the absence of adequate dietary sodium restriction. Confirmation studies with hard end points are necessary, but in the meantime a coordinated effort to implement the guidelines on sodium intake is warranted. Our findings support the combined endeavours of patients and health professionals to accomplish persistent sodium restriction to improve the efficacy of renoprotective treatment.

We thank Nynke Halbesma, epidemiologist at the department of internal medicine, division of nephrology, University Medical Center Groningen, for her help in the statistical analyses of the results. We also thank Folkert W Visser, Jan A Krikken, and Arjan Kwakernaak from the department of internal medicine, division of nephrology, University Medical Center Groningen for their help in collecting the data.

Contributors: MCJS and FW contributed equally. MCJS collected data, did the analyses, and wrote the manuscript. FW designed the study, collected data, and wrote the manuscript. MHH and A-JW facilitated the execution of the study and wrote the manuscript. WMTJ, HLH, and GDL contributed to the analyses and wrote the manuscript. GN designed the study, facilitated the execution of the study, contributed to the analyses, and wrote the manuscript. GDL is the guarantor.

Funding: The study was supported by an unrestricted grant from Novartis (CVAL489ANL08). The funding source had no role in the design and conduct of the study; collection, management, analysis, and interpretation of the data; and preparation, review, or approval of the manuscript.

Competing interests: All authors have completed the Unified Competing Interest form at www.icmje.org/coi_disclosure.pdf (available on request from the corresponding author) and declare that GN has support from Novartis for the submitted work; none of the authors had a relationship with a company that might have an interest in the submitted work in the previous 3 years; and MCJS, FW, MHH, A-JW, WMTJ, HLH, and GDL have no non-financial interests that may be relevant to the submitted work.

Ethical approval: The institutional ethics committee at each centre approved the protocol. All participants gave written informed consent. Data sharing: No additional data available.

1 Lewis EJ, Hunsicker LG, Bain RP, Rohde RD. The effect of angiotensin-converting-enzyme inhibition on diabetic nephropathy. N Engl J Med 1993;329:1456-62.

2 Brenner BM, Cooper ME, de Zeeuw D, Keane WF, Mitch WE, Parving HH, et al. Effects of losartan on renal and cardiovascular outcomes in patients with type 2 diabetes and nephropathy. N Engl J Med 2001;345:861-9.

3 Jafar TH, Stark PC, Schmid CH, Landa M, Maschio G, de Jong PE, et al. Progression of chronic kidney disease: the role of blood pressure control, proteinuria, and angiotensin-converting enzyme inhibition: a patient-level meta-analysis. Ann Intern Med 2003;139:244-52.

4 Peterson JC, Adler S, Burkart JM, Greene T, Hebert LA, Hunsicker LG, et al. Blood pressure control, proteinuria, and the progression of renal disease: the Modification of Diet in Renal Disease Study. Ann Intern Med 1995;123:754-62.

5 Basi S, Lewis JB. Microalbuminuria as a target to improve cardiovascular and renal outcomes. Am J Kidney Dis 2006;47:927-46.

6 Ruggenenti P, Schieppati A, Remuzzi G. Progression, remission, regression of chronic renal diseases. Lancet 2001;357:1601-8.

7 Kidney Disease Outcomes Quality Initiative. K/DOQI clinical practice guidelines on hypertension and antihypertensive agents in chronic kidney disease. Am J Kidney Dis 2004;43:S1-290.

8 Kunz R, Friedrich C, Wolbers M, Mann JF. Meta-analysis: effect of monotherapy and combination therapy with inhibitors of the renin angiotensin system on proteinuria in renal disease. Ann Intern Med 2008;148:30-48.

9 Thomas MC. The assessment and management of albuminuria in primary care. Diabetes Res Clin Pract 2008;80:83-8.

10 Slagman MC, Navis G, Laverman GD. Dual blockade of the renin-angiotensin-aldosterone system in cardiac and renal disease. Curr Opin Nephrol Hypertens 2010;19:140-52.

11 Ruggenenti P, Perticucci E, Cravedi P, Gambara V, Costantini M, Sharma SK, et al. Role of remission clinics in the longitudinal treatment of CKD. J Am Soc Nephrol 2008;19:1213-24.

12 Rossing K, Schjoedt KJ, Jensen BR, Boomsma F, Parving HH. Enhanced renoprotective effects of ultrahigh doses of irbesartan in patients with type 2 diabetes and microalbuminuria. Kidney Int 2005;68:1190-8.

13 Laverman GD, Remuzzi G, Ruggenenti P. ACE inhibition versus angiotensin receptor blockade: which is better for renal and cardiovascular protection? J Am Soc Nephrol 2004; 15:S64-70.

14 Laverman GD, Henning RH, de Jong PE, Navis G, de Zeeuw D. Optimal antiproteinuric dose of losartan in nondiabetic patients with nephrotic range proteinuria. Am J Kidney Dis 2001:38:1381-4

15 Catapano F, Chiodini P, De Nicola L, Minutolo R, Zamboli P, Gallo C, et al. Antiproteinuric response to dual blockade of the renin-angiotensin system in primary glomerulonephritis: meta-analysis and metaregression. Am J Kidney Dis 2008;52:475-85

16 Vogt L, Waanders F, Boomsma F, de Zeeuw D, Navis G. Effects of dietary sodium and hydrochlorothiazide on the antiproteinuric efficacy of losartan. J Am Soc Nephrol 2008:19:999-1007.

17 Buter $\mathrm{H}$, Hemmelder MH, Navis G, de Jong PE, de Zeeuw D. The blunting of the antiproteinuric efficacy of ACE inhibition by high sodium intake can be restored by hydrochlorothiazide. Nephrol Dial Transplant 1998;13:1682-5.

18 Heeg JE, de Jong PE, van der Hem GK, de Zeeuw D. Efficacy and variability of the antiproteinuric effect of ACE inhibition by lisinopril. Kidney Int 1989;36:272-9.

19 Esnault VL, Ekhlas A, Delcroix C, Moutel MG, Nguyen JM. Diuretic and enhanced sodium restriction results in improved antiproteinuric response to RAS blocking agents. J Am Soc Nephrol 2005;16:474-81.

20 Houlihan CA, Allen TJ, Baxter AL, Panangiotopoulos S, Casley DJ, Cooper ME, et al. A low-sodium diet potentiates the effects of losartan in type 2 diabetes. Diabetes Care 2002;25:663-71.

21 Ekinci El, Thomas G, Thomas D, Johnson C, Macisaac RJ, Houlihan CA, et al. Effects of salt supplementation on the albuminuric response to telmisartan with or without hydrochlorothiazide therapy in hypertensive patients with type 2 diabetes are modulated by habitual dietary salt intake. Diabetes Care 2009;32:1398-403.

22 Weir MR, Dengel DR, Behrens MT, Goldberg AP. Salt-induced increases in systolic blood pressure affect renal hemodynamics and proteinuria. Hypertension 1995;25:1339-44.

23 Suzuki T, Miyazaki Y, Shimizu A, Ito Y, Okonogi H, Ogura M, et al. Sodium-sensitive variability of the antiproteinuric efficacy of RAS inhibitors in outpatients with IgA nephropathy. Clin Nephrol 2009;72:274-85. 


\section{What is already known on this topic}

Monotherapy with angiotensin converting enzyme (ACE) inhibition or angiotensin receptor blockade is often insufficient to reach treatment targets for proteinuria and blood pressure in patients with renal disease

The combination of ACE inhibition and angiotensin receptor blockade (dual blockade) is widely used but induces only a modest additional reduction of proteinuria and blood pressure

Dietary sodium intake in patients with renal disease is usually higher than recommended

\section{What this study adds}

Moderate dietary sodium restriction is considerably more effective than dual blockade for control of proteinuria and blood pressure

Addition of angiotensin receptor blockade may still be useful in patients treated with ACE inhibition who have insufficient control of proteinuria or blood pressure despite adequate sodium restriction

24 Navis G, de Jong P, Donker AJ, van der Hem GK, de Zeeuw D. Diuretic effects of angiotensin-converting enzyme inhibition: comparison of low and liberal sodium diet in hypertensive patients. J Cardiovasc Pharmacol 1987;9:743-8.

25 Laverman GD, Navis G, Henning RH, de Jong PE, de Zeeuw D. Dual renin-angiotensin system blockade at optimal doses for proteinuria. Kidney Int 2002:62:1020-5.

26 Retraction-combination treatment of angiotensin-II receptor blocker and angiotensin-converting-enzyme inhibitor in non-diabetic renal disease (COOPERATE): a randomised controlled trial. Lancet 2009;374:1226.

27 Yusuf S, Teo KK, Pogue J, Dyal L, Copland I, Schumacher H, et al. Telmisartan, ramipril, or both in patients at high risk for vascular events. N Engl J Med 2008:358:1547-59.

28 Van Zuilen AD, Wetzels JF, Bots ML, Van Blankestijn PJ. MASTERPLAN: study of the role of nurse practitioners in a multifactorial intervention to reduce cardiovascular risk in chronic kidney disease patients. J Nephrol 2008;21:261-7.

29 De Nicola L, Minutolo R, Chiodini P, Zoccali C, Castellino P, Donadio C, et al. Global approach to cardiovascular risk in chronic kidney disease: reality and opportunities for intervention. Kidney Int 2006;69:538-45.

30 The GISEN Group (Gruppo Italiano di Studi Epidemiologici in Nefrologia). Randomised placebo-controlled trial of effect of ramipril on decline in glomerular filtration rate and risk of terminal renal failure in proteinuric, non-diabetic nephropathy. Lancet 1997;349:1857-63.

31 Krikken JA, Lely AT, Bakker SJ, Navis G. The effect of a shift in sodium intake on renal hemodynamics is determined by body mass index in healthy young men. Kidney Int 2007;71:260-5.

32 Maroni BJ, Steinman TI, Mitch WE. A method for estimating nitrogen intake of patients with chronic renal failure. Kidney Int 1985;27:58-65.

33 Masud T, Manatunga A, Cotsonis G, Mitch WE. The precision of estimating protein intake of patients with chronic renal failure. Kidney Int 2002;62:1750-6.

34 Correa JA, Bellavance F. Power comparison of robust approximate and non-parametric tests for the analysis of cross-over trials. Stat Med 2001;20:1185-96.

35 Zhou J, Yuan Y, Reynolds R, Raber S, Li Y. Cost-efficient higher-order crossover designs in comparative bioavailability studies. Clin Pharmacokinet 2006;45:623-32.

36 Korgaonkar S, Tilea A, Gillespie BW, Kiser M, Eisele G, Finkelstein F, et al. Serum potassium and outcomes in CKD: insights from the RRI-CKD cohort study. Clin J Am Soc Nephrol 2010;5:762-9.

37 Einhorn LM, Zhan M, Hsu VD, Walker LD, Moen ME, Seliger SL, et al. The frequency of hyperkalemia and its significance in chronic kidney disease. Arch Intern Med 2009:169:1156-62.

38 Apperloo AJ, de Zeeuw D, de Jong PE. A short-term antihypertensive treatment-induced fall in glomerular filtration rate predicts long-term stability of renal function. Kidney Int 1997;51:793-7.
39 Hansen HP, Rossing P, Tarnow L, Nielsen FS, Jensen BR, Parving HH. Increased glomerular filtration rate after withdrawal of long-term antihypertensive treatment in diabetic nephropathy. Kidney Int 1995;47:1726-31.

40 Bakris GL, Weir MR. Angiotensin-converting enzyme inhibitor-associated elevations in serum creatinine: is this a cause for concern? Arch Intern Med 2000;160:685-93.

41 Slagman MC, Navis G, Laverman GD. Reversible effects of diuretics added to renin-angiotensin-aldosterone system blockade: impact on interpretation of long-term kidney function outcome. Am J Kidney Dis 2010;56:601-2.

42 Esnault VL, Ekhlas A, Nguyen JM, Moranne O. Diuretic uptitration with half dose combined ACEI + ARB better decreases proteinuria than combined ACEI + ARB uptitration. Nephro Dial Transplant 2010;25:2218-24

43 Brown IJ, Tzoulaki I, Candeias V, Elliott P. Salt intakes around the world: implications for public health. Int J Epidemiol 2009;38:791-813.

44 Vallon V, Blantz R, Thomson S. The salt paradox and its possible implications in managing hypertensive diabetic patients. Curr Hypertens Rep 2005;7:141-7.

45 Pijls LT, de Vries H, Donker AJ, van Eijk JT. The effect of protein restriction on albuminuria in patients with type 2 diabetes mellitus: a randomized trial. Nephrol Dial Transplant 1999;14:1445-53.

46 Levey AS, Greene T, Beck GJ, Caggiula AW, Kusek JW, Hunsicker LG, et al. Dietary protein restriction and the progression of chronic renal disease: what have all of the results of the MDRD study shown? J Am Soc Nephrol 1999;10:2426-39.

47 Heaney RP. Role of dietary sodium in osteoporosis. J Am Coll Nutr 2006;25:271-6S.

48 Pfeffer MA, McMurray JJ, Velazquez EJ, Rouleau JL, Køber L, Maggioni AP, et al . Valsartan, captopril, or both in myocardial infarction complicated by heart failure, left ventricular dysfunction, or both. N Engl J Med 2003;349:1893-906.

$49 \mathrm{He}$ FJ, MacGregor GA. Effect of longer-term modest salt reduction on blood pressure. Cochrane Database Syst Rev 2004;1:CD004937.

50 Cook NR, Cutler JA, Obarzanek E, Buring JE, Rexrode KM, Kumanvika SK, et al. Long term effects of dietary sodium reduction on cardiovascular disease outcomes: observational follow-up of the trials of hypertension prevention (TOHP). BMJ 2007:334:885.

51 Bibbins-Domingo K, Chertow GM, Coxson PG, Moran A, Lightwood JM, Pletcher MJ, et al. Projected effect of dietary salt reductions on future cardiovascular disease. $N$ Engl $J$ Med 2010;362:590-9.

52 Strazzullo P, D'Elia L, Kandala NB, Cappuccio FP. Salt intake, stroke, and cardiovascular disease: meta-analysis of prospective studies. BMJ 2009;339:b4567.

Accepted: 13 May 2011

Cite this as: BMJ 2011;343:d4366 


\section{Tables}

\section{Table 1| Baseline ${ }^{*}$ characteristics. Values are numbers of patients unless stated otherwise}

\begin{tabular}{|c|c|c|c|c|}
\hline \multirow[b]{2}{*}{ Characteristics } & \multicolumn{4}{|c|}{ Treatment sequence $†$} \\
\hline & $1(n=14)$ & $2(n=11)$ & $3(n=13)$ & $4(n=14)$ \\
\hline Mean (SE) age (years) & $53(3)$ & $55(3)$ & $51(4)$ & $47(4)$ \\
\hline Male sex & 64 & 82 & 92 & 93 \\
\hline White ethnicity & 14 & 11 & 13 & 14 \\
\hline Mean (SE) body mass index $\left(\mathrm{kg} / \mathrm{m}^{2}\right)$ & $27(1)$ & $28(1)$ & $28(1)$ & $28(1)$ \\
\hline \multicolumn{5}{|l|}{ Renal diagnosis: } \\
\hline IgA nephropathy & 3 & 2 & 4 & 6 \\
\hline Focal segmental glomerulosclerosis & 3 & 7 & 3 & 3 \\
\hline Membranous nephropathy & 2 & 0 & 2 & 3 \\
\hline Hypertensive nephropathy & 1 & 2 & 3 & 0 \\
\hline Other/inconclusive & 5 & 0 & 1 & 2 \\
\hline \multicolumn{5}{|l|}{ Use of non-study drugsł: } \\
\hline$\beta$ blocker & 4 & 2 & 4 & 2 \\
\hline Calcium channel blocker & 1 & 4 & 3 & 2 \\
\hline a blocker & 0 & 1 & 3 & 1 \\
\hline Diuretic & 3 & 1 & 3 & 6 \\
\hline Lipid lowering agent & 7 & 7 & 7 & 4 \\
\hline Mean (SE) systolic blood pressure $(\mathrm{mm} \mathrm{Hg})$ & $131(4)$ & $135(4)$ & $135(7)$ & $123(4)$ \\
\hline Mean (SE) diastolic blood pressure $(\mathrm{mm} \mathrm{Hg})$ & $78(2)$ & $78(3)$ & $78(4)$ & $71(3)$ \\
\hline Geometric mean $(95 \% \mathrm{Cl})$ proteinuria (g/24 hours) & 1.5 (0.9 to 2.4$)$ & $2.0(1.3$ to 3.0$)$ & $1.5(0.9$ to 2.6$)$ & $1.5(0.8$ to 2.6$)$ \\
\hline $\begin{array}{l}\text { Geometric mean }(95 \% \mathrm{Cl}) \text { creatinine clearance } \\
(\mathrm{mL} / \mathrm{min})\end{array}$ & 70 (56 to 88$)$ & 60 (41 to 89$)$ & 74 (56 to 98$)$ & 78 (56 to 107$)$ \\
\hline $\begin{array}{l}\text { Mean (SE) urinary sodium excretion (mmol/24 } \\
\text { hours) }\end{array}$ & $166(23)$ & $161(14)$ & $197(20)$ & $182(22)$ \\
\hline
\end{tabular}

*Data at end of run-in period taken as baseline values.

$\dagger 1=$ placebo-low sodium diet, valsartan-low sodium diet, valsartan-regular sodium diet, placebo-regular sodium diet; 2=placebo-regular sodium diet, valsartan-regular sodium diet, valsartan-low sodium diet, placebo-low sodium diet; $3=$ valsartan-regular sodium diet, placebo-regular sodium diet, placebo-low sodium diet, valsartan-low sodium diet; $4=$ =valsartan-low sodium diet, placebo-low sodium diet, placebo-regular sodium diet, valsartan-regular sodium diet; no significant differences in baseline values were found.

$\ddagger$ Kept stable during study. 


\begin{tabular}{|c|c|c|c|c|}
\hline & \multicolumn{2}{|c|}{ Regular sodium diet } & \multicolumn{2}{|c|}{ Low sodium diet } \\
\hline & ACE inhibitor & ACE inhibitor-ARB & ACE inhibitor & ACE inhibitor-ARB \\
\hline \multicolumn{5}{|l|}{ Plasma } \\
\hline Sodium (mmol/L) & $140.7(0.4)$ & $140.8(0.4)$ & $139.5(0.4)^{*} \dagger$ & $139.1(0.4)^{*} \dagger$ \\
\hline Potassium (mmol/L) & $4.6(0.1)$ & $4.6(0.1)$ & $4.7(0.1)^{\star}$ & $5.0(0.1)^{\star} † \ddagger$ \\
\hline Creatinine $(\mu \mathrm{mol} / \mathrm{L})$ & $137(8)$ & $137(8)$ & $149(9)^{\star}$ & $157(9)^{\star} \dagger$ \\
\hline Urea $(\mathrm{mmol} / \mathrm{L})$ & $9.8(0.7)$ & $10.2(0.7)$ & $11.8(0.8)^{*} \dagger$ & $12.9(0.8)^{*} \dagger$ \\
\hline Albumin (g/L) & $38(1)$ & $39(1)$ & $40(1)^{\star} \dagger$ & $40(1)^{\star} \dagger$ \\
\hline Total protein $(\mathrm{g} / \mathrm{L})$ & $68(1)$ & $69(1)$ & $71(1)^{*}$ & $72(1)^{*} \dagger$ \\
\hline Total cholesterol (mmol/L) & $5.1(0.2)$ & $5.0(0.2)$ & $4.8(0.1)$ & $4.9(0.2)$ \\
\hline \multicolumn{5}{|l|}{ Urine } \\
\hline Creatinine (mmol/24 hours) & $13.8(0.6)$ & $14.0(0.5)$ & $13.5(0.6)$ & $13.4(0.6)$ \\
\hline Sodium (mmol/24 hours) & $189(8)$ & $180(9)$ & $106(7)^{*} \dagger$ & $105(8)^{\star} \dagger$ \\
\hline Urea (mmol/24 hours) & $395(18)$ & $403(19)$ & $359(17)^{\star} \dagger$ & $352(19)^{*} \dagger$ \\
\hline Potassium (mmol/24 hours) & $78(3)$ & $76(4)$ & $76(4)$ & $73(3)$ \\
\hline Calcium (mmol/24 hours) & $1.2(0.9$ to 1.5$)$ & $1.0(0.7 \text { to } 1.3)^{\star}$ & $0.7(0.6 \text { to } 0.9)^{\star}$ & $0.7(0.5 \text { to } 0.9)^{*} \dagger$ \\
\hline Creatinine clearance $(\mathrm{mL} / \mathrm{min})$ & 72 (62 to 84 ) & 74 (65 to 84$)$ & $66(57 \text { to } 76)^{*} \dagger$ & $61(53 \text { to } 70)^{*} \dagger$ \\
\hline Protein/creatinine ratio $(\mathrm{mg} / \mathrm{mg})$ & $1.2(0.9$ to 1.5$)$ & $0.9(0.7 \text { to } 1.3)^{*}$ & $0.6(0.4 \text { to } 0.8)^{*} \dagger$ & $0.5(0.3 \text { to } 0.7)^{\star}+\ddagger$ \\
\hline \multicolumn{5}{|l|}{ Other } \\
\hline Body weight $(\mathrm{kg})$ & $89(3)$ & $89(2)$ & $87(2)^{*} \dagger$ & $87(2)^{\star} \dagger$ \\
\hline Oedema (No of patients) & 18 & 20 & $8 \dagger$ & $4^{*} \dagger$ \\
\hline Symptomatic hypotension (number) & 0 & 0 & 3 & 4 \\
\hline Dry cough (number) & 1 & 1 & 1 & 1 \\
\hline $\begin{array}{l}A C E=\text { Angiotensin converting enzym } \\
{ }^{*} P<0.01 \text { versus } A C E \text { inhibitor on reg } \\
+P<0.01 \text { versus } A C E \text { inhibitor- } A R B \\
\ddagger P<0.01 \text { versus } A C E \text { inhibitor on lov }\end{array}$ & $\begin{array}{l}\text { e; ARB=angioten } \\
\text { yular sodium diet. } \\
\text { on regular sodium } \\
N \text { sodium diet. }\end{array}$ & $\begin{array}{l}\text { nsin receptor blocker. } \\
\text { m diet. }\end{array}$ & & \\
\hline
\end{tabular}




\section{Figures}

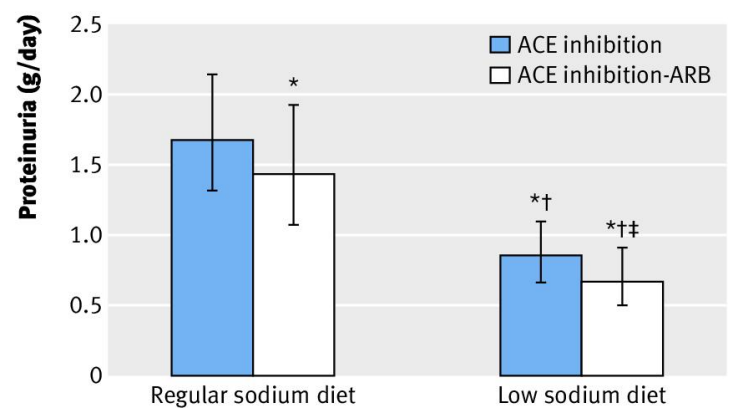

Fig 1 Additional effect of low sodium diet, angiotensin receptor blockade (ARB), or both on proteinuria during angiotensin converting enzyme (ACE) inhibition. Data are geometric mean with $95 \%$ confidence interval. ${ }^{*} \mathrm{P}<0.05 v$ ACE inhibition on regular sodium diet. $\uparrow \mathrm{P}<0.05 \vee \mathrm{ACE}$ inhibition plus $\mathrm{ARB}$ on regular sodium diet. $\ddagger \mathrm{P}<0.05 \vee \mathrm{ACE}$ inhibition on low sodium diet

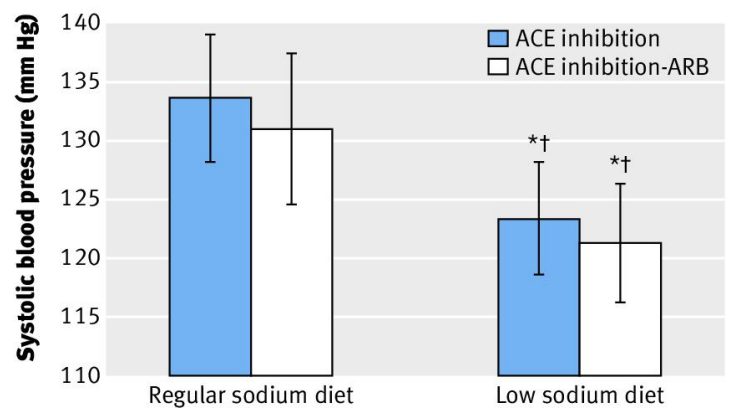

Fig 2 Additional effect of low sodium diet, angiotensin receptor blockade (ARB), or both on systolic blood pressure during angiotensin converting enzyme (ACE) inhibition. Data are mean with $95 \%$ confidence interval. ${ }^{*} \mathrm{P}<0.05 v \mathrm{ACE}$ inhibition on regular sodium diet. $+\mathrm{P}<0.05 v \mathrm{ACE}$ inhibition plus $\mathrm{ARB}$ on regular sodium diet

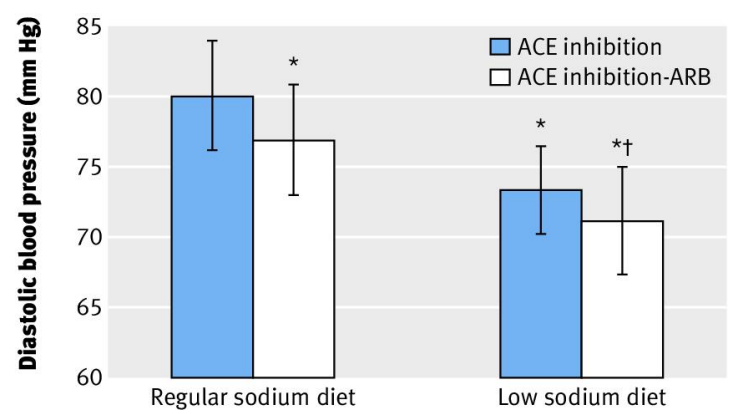

Fig 3 Additional effect of low sodium diet, angiotensin receptor blockade (ARB), or both on diastolic blood pressure during angiotensin converting enzyme (ACE) inhibition. Data are mean with $95 \%$ confidence interval. ${ }^{*} P<0.05 v$ ACE inhibition on regular sodium diet. $\nmid \mathrm{P}<0.05 \vee$ ACE inhibition plus ARB on regular sodium diet 